\title{
MASS MEDIA COMMUNICATION OF EMERGENCY ISSUES AND COUNTERMEASURES IN A NUCLEAR ACCIDENT: FUKUSHIMA REPORTING IN EUROPEAN NEWSPAPERS
}

\author{
Eduardo Gallego $^{1, *}$, Marie Claire Cantone ${ }^{2}$, Deborah H. Oughton ${ }^{3}$, Tanja Perko ${ }^{4}$, Iztok Prezelj ${ }^{5}$ and \\ Yevgeniya Tomkiv ${ }^{3}$ \\ ${ }^{1}$ Energy Engineering Department, E.T.S. Ingenieros Industriales, Universidad Politécnica de Madrid, José \\ Gutiérrez Abascal, 2, 280o6-Madrid, Spain \\ ${ }^{2}$ Facoltà di Medicina e Chirurgia, Dipartimento di Fisica, Università degli Studi di Milano, Via Celoria 16, I- \\ 20133 Milano, Italy \\ ${ }^{3}$ Centre for Environmental Radioactivity (CERAD), Norwegian University of Life Sciences, \\ Universitetstunet 3, 1433 Ås, Norway \\ ${ }^{4}$ Institute for Environment, Health and Safety, Belgian Nuclear Research Centre SCK·CEN, Boeretang 20o, B- \\ 2400 Mol, Belgium \\ ${ }^{5}$ Faculty of Social Sciences, University of Ljubljana, Ljubljana, Slovenia \\ ${ }^{*}$ Corresponding author: eduardo.gallego@upm.es
}

\begin{abstract}
This paper presents the results of a large study of 1340 articles published by two major newspapers in six European countries (Belgium, Italy, Norway, Slovenia, Spain and Russia) in the first 2 months after the Fukushima Daiichi nuclear disaster. The focus of the analysis is on the application and overall impact of protective actions, both during the emergency phase and later, how the newspapers describe those actions, which differences were apparent between countries and what recommendations can be extracted in order to improve general communication about these issues. Aclear lesson is that, even under uncertainty and recognising limitations, responsible authorities need to provide transparent, clear and understandable information to the public and the mass media right from the beginning of the early phase of any nuclear emergency. Clear, concise messages should be given. Mass media could play a key role in reassuring the public if the countermeasures are clearly explained.
\end{abstract}

\section{INTRODUCTION}

Communicating effectively with the public about radiation emergencies is key to successful emergency management. It will help mitigate the risks, support the implementation of protective actions and contribute to minimising negative psychological impacts ${ }^{(1,}$ 2). The importance of public communication has been highlighted during all the historical nuclear emergencies, and the recent disaster at the Fukushima Daiichi nuclear power plant (NPP) has shown that there are still gaps to be filled in nuclear and radiological preparedness. The European PREPARE project [Innovative integrated tools and platforms for radiological emergency preparedness and post-accident response in Europe. EURATOM Seventh Framework Programme FP7/2012-2013, grant agreement number 323287] was aimed to close those gaps, having one of the work packages investigating the means for relevant, reliable and trustworthy information to be made available to public at the appropriate time and according to its needs, both during the nuclear emergency and post-emergency phase ${ }^{(3)}$.

A relevant task was the study of traditional media coverage during the first 2 months after the Fukushima nuclear accident in six countries (Belgium, Italy, Norway, Slovenia, Spain and Russia). These countries faced similar radiological consequences due to the Fukushima accident, and each of them had a different status related to nuclear energy production: phasing out (Belgium), referendum about (Italy) and active (Spain, Russia and Slovenia), and no-nuclear energy production (Norway). In total, 1340 articles published by two major newspapers in each country were analysed with focus on the application and overall impact of protective actions, both during the emergency phase and later, how the newspapers describe those actions, which differences were apparent between countries and what recommendations can be extracted in order to improve general communication about these issues.

\section{METHODS AND TOPICS ANALYSED}

A media content analysis of 12 leading newspapers was conducted in six countries ${ }^{(4)}$ : Le Soir and De Standaard in Belgium $(N=260)$; Corriere della Sera and La Repubblica in Italy ( $N=270)$; Aftenposten and Dagsavisen in Norway $(N=133)$; Komsomolskaya Pravda and Izvestiya in Russia $(N=172)$; Večer and Delo in Slovenia $(N=158)$; and El País and El Mundo in Spain $(N=315)$. The articles coded $(N=1340)$ were directly or indirectly related to the Fukushima 
nuclear accident by containing the words 'nuclear' and 'Fukushima', and were published between 11 March 2011 and 11 May 2011. Information in the media articles was coded using standard methods for content analysis $^{(5)}$ and detailed in the specific code book developed for the research. Each article was coded by two independent coders for each language, plus a master coder who made decisions on the code in the case of disagreement. All the coders received training prior to the start of the coding procedure. The inter-coder reliability was calculated using Krippendorf's alpha ${ }^{(8)}$, which is a reliability coefficient developed to measure the agreement between observers and coders.

Results are described over time and for every country. The first variable considered in this paper is the emphasis of the articles on the different phases of the emergency management cycle: 'Preparedness' is seen as a collection of topics addressing emergency planning and certain other issues like pre-distribution of iodine tablets or the stress tests on nuclear installations to check their capacity against extreme natural events or to severe accidents. 'Crisis Response', which comprises the majority of the articles, is more related to immediate happenings, actions and decisions in the aftermath of the accident. Examples include communication about the INES scale, food restrictions, costs, number of people being affected and evacuated, as well as on-site actions undertaken at the NPP, e.g. in order to regain control over the situation. The last phase, 'Recovery and Evaluation', is more related to longterm recovery actions and evaluations like waste management or the general evaluation of the future of nuclear energy after this disaster. This also affects longterm societal, political and economic effects in general.

Next, the focus is put on some issues related to emergency management, like the actions undertaken by the emergency workers to control the damaged nuclear plant, topics related with other emergency actors and actions implemented, or the information to the public of Japan and the rest of the world.

The most commonly considered urgent protective measures in a nuclear or radiological emergency are evacuation, decontamination of individuals, sheltering, respiratory protection, iodine thyroid blocking and restriction of the consumption of foodstuffs that have the potential to give significant exposures to people (e.g. green vegetables grown in the open and milk from animals grazing outdoors). Since the period covered by the study is restricted to 2 months after the beginning of the accident (from 11 March till 11 May 2011), some of the actions adopted by the Japanese authorities after that period, such as long-term evacuation, agricultural protective measures and decontamination measures, were not implemented yet and are obviously not considered in the articles analysed. Thus, the third category of articles analysed was focused on countermeasures other than food and on food control actions.

\section{RESULTS AND ANALYSIS \\ Emphasis on the phases of the emergency management cycle}

As can be observed in Figure 1, the results show that there was a low focus on preparedness and a high focus on crisis response and recovery/evaluation. In the first 5 weeks, the main focus was on crisis response. Around Week 6, the main focus shifted to the recovery/evaluation phase, although in the first week after the accident already around 30\% of the

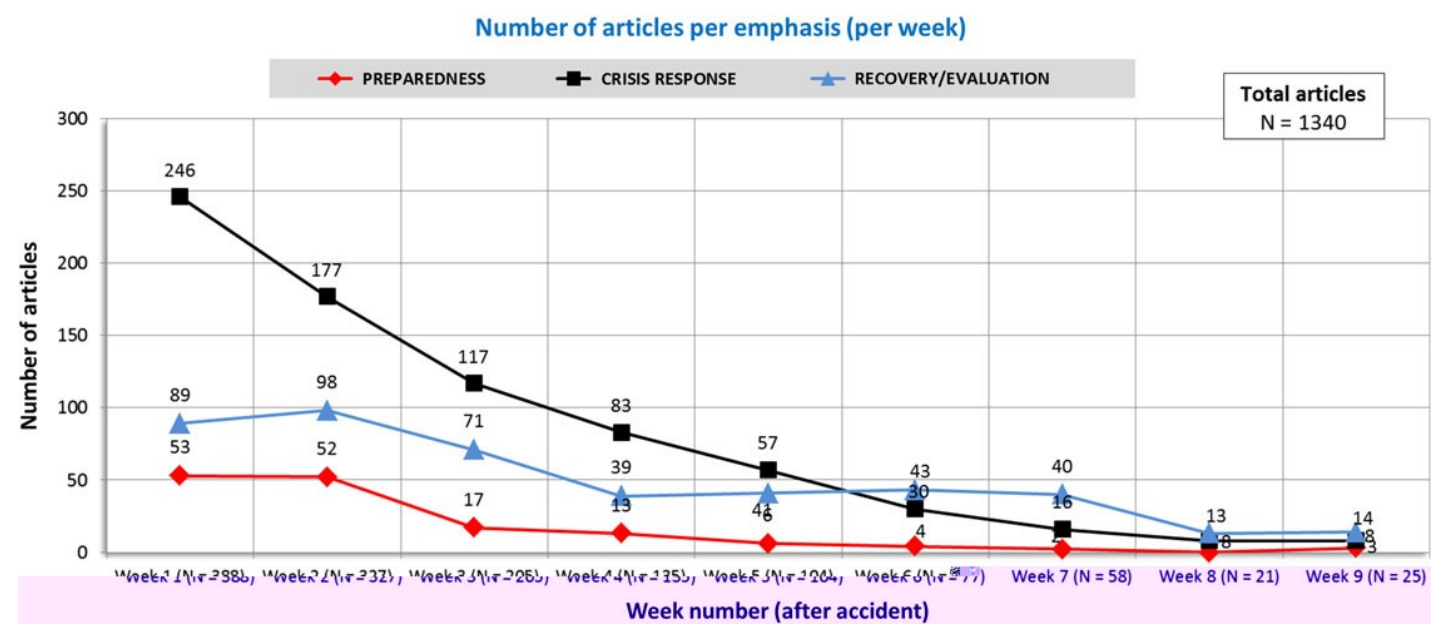

Figure 1. Distribution of the total number of articles according to the emphasis on the different phases of the accident per week. 
articles focused on the recovery/evaluation phase. The focus on the preparedness phase was low across all weeks.

There are some differences between countries, however (see F igure 2). Spain, Belgium and Russia stand out with a high focus on the crisis response phase. In Russia, this is firstly related to the discussion if the situation on Fukushima NPP could have been dangerous for Russian Far East as Russian, Chinese and Korean territories are the closest to Japan. Examples of articles are 'Far East buys up dosimeters and yodomarin' [potassium iodide] and 'The radioactive cloud is not dangerous for Russia'. The second reason is that Russian rescuers were sent to Japan in relation to natural disaster consequences and were working there just during the acute phase of the Fukushima accident (e.g. the article 'Our rescuers may stop working due to radiation'). In addition, two Russian nuclear specialists were sent to Japan. One more reason is that having 10 NPPs in Russia and the Chernobyl experience, Russian nuclear specialists actively discussed and commented the ongoing Fukushima situation.

Italy, Slovenia and Norway focused more on the recovery phase. In the case of Italy and Slovenia, the reason seems to be that in these countries, media paid much attention to the future of nuclear energy. In Italy, the percentage of articles about recovery phase focusing on future of nuclear energy was $\sim 65 \%$, and in Slovenia, $\sim 50 \%$. In the case of Norway, it could be assumed that due to Chernobyl accident, the country has more experience in recovery actions than in crisis response at a plant.

\section{Emergency management issues}

Two hundred and thirty-five articles were addressing emergency management issues with a high relevance given to the actions of the emergency workers to control the damaged nuclear plant. Actions undertaken to re-establish cooling of the reactors and the spent fuel cooling pools, to re-establish electrical supply at the plant, to extinguish fires and to mitigate the impact of the explosions, as well as to monitor radiation levels, received significant attention in the first 4 weeks (see Figure 3 ).

The next issue by relevance was information to the public and the rest of the world. Criticisms to the opacity of the Japanese government were the topic in several articles in the first week, which later shifted to analysing distrust of the population on their authorities. This was indeed a very relevant question with regard to communication, and the media reflected it accordingly.

Other issues related to the emergency actors and actions implemented by the army, fire brigades, civil protection or volunteers, related to control and support to evacuees, radiological monitoring of people and the environment, etc. received in general less attention by the media.

\section{Protective actions (not affecting food)}

The explicit topic of countermeasures like evacuation, sheltering, iodine thyroid blocking, measurement of contamination in people (both external and internal), monitoring of the contamination in the

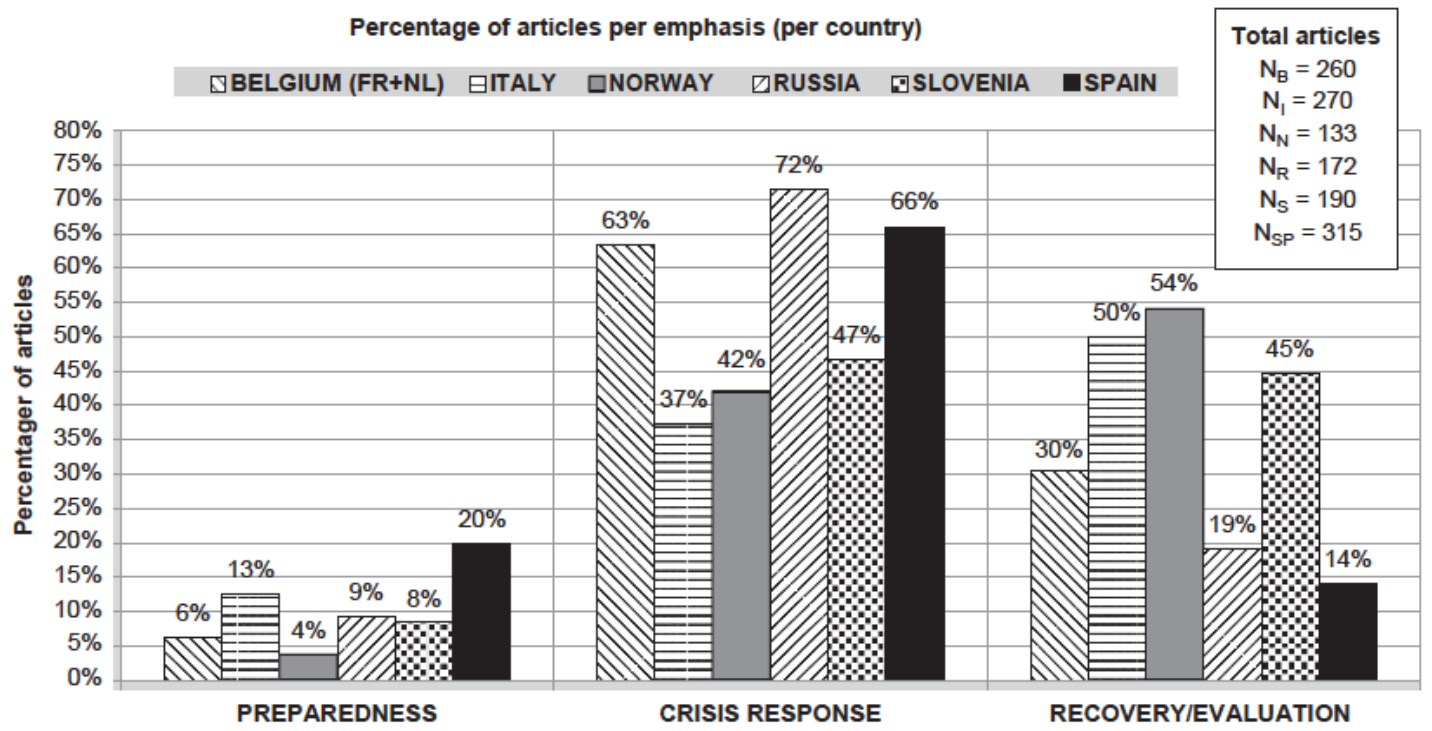

Figure 2. Distribution of the percentage of articles according to the emphasis on the different phases of the accident per country. 
Number of articles with emergency management issues per week (global)

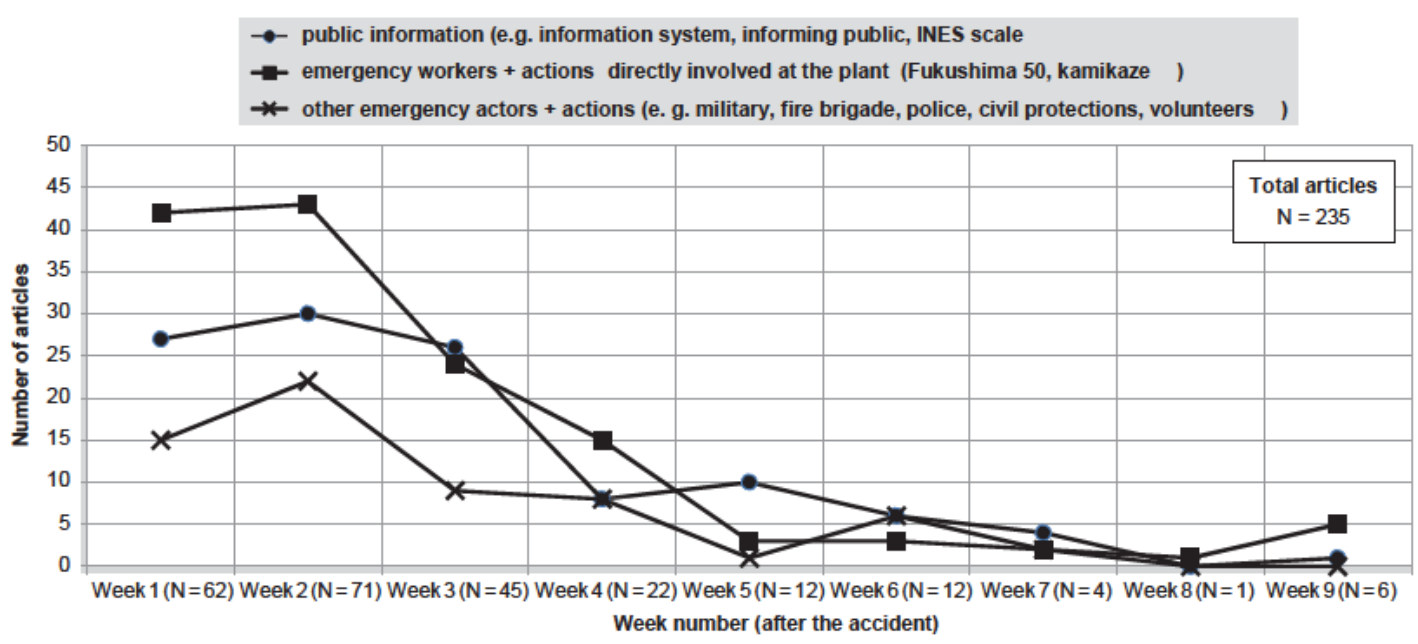

Figure 3. Number of articles dealing with emergency management issues covered by the media per week (weekly number of articles in the labels of abscises axis).

environment and its decontamination was not addressed as the main topic in many articles, with only 97 out of a total of 1340 printed articles. Reflecting a clear interest on the human dimension of the accident, the total number of articles having those countermeasures as the main topic was higher in Spain (41) than in the other countries: Belgium (14), Italy (16), Norway (12), Slovenia (7) and Russia (7). Figure 4 displays a distribution of these topics by countries. Normally, articles dealt about more than one type of countermeasure.

Looking to the time distribution of the articles, represented in Figure 5, it can be observed that of those protective actions, in the first 3 weeks after the accident, evacuation obviously received a significantly larger attention than other countermeasures. However, long-duration sheltering of the population, measurement of people's contamination, especially of iodine in thyroid of children, and the use of iodine tablets as a prophylactic measure were also topics frequently found in the media.

The monitoring of radiation levels in the territories around Fukushima-Daiichi NPP also deserved several articles, while decontamination, a typical countermeasure of the recovery phase, was treated just in a few articles at these early stages of the accident.

\section{Protective actions on food}

Published articles with food countermeasures as the main topic were relatively scarce at the early period considered in the study: only 58 articles $(\sim 4.3 \%$ of the 1340 total articles analysed). The main issues were related to protective measures affecting drinking water (in 21 articles), farming products (in 21 articles), fish and sea food (23 articles), restrictions on food products (consumption, producing, etc., in 25 products), food control (in 34 articles) and other issues related to food (9 articles). A particularly relevant topic in European countries was food exports from Japan, treated in 36 articles, because of warning news arising just after the initiation of the accident concerning the presence of radioactivity in drinking water and food.

Many articles discussed several of the topics simultaneously, given their strong overlapping. This overlapping of topics can be observed, for instance, in the case of Spanish newspapers, where only 17 articles focused on food countermeasures, while many of them considered several topics. The distribution of topics on protective actions affecting food by countries is shown in Figure 6. It is quite surprising than in countries like Slovenia or Norway, the number of articles on these issues is extremely low. Spain and Russia have the largest number of articles, with Belgium and Italy sharing a moderate number of articles on food countermeasures.

Looking at the distribution of published articles with time, which is shown in Table 1 , it can be observed that the second week concentrated the largest number of articles (25). All the topics were included, with more attention on food control measures, import and export of food, and drinking water control, which at that time was implemented in several Japanese cities, particularly in Tokyo. Later, natural decay of iodine isotopes, which were the main pollutants in drinking water, made this question decline. Control of sea food and fish was attracting 


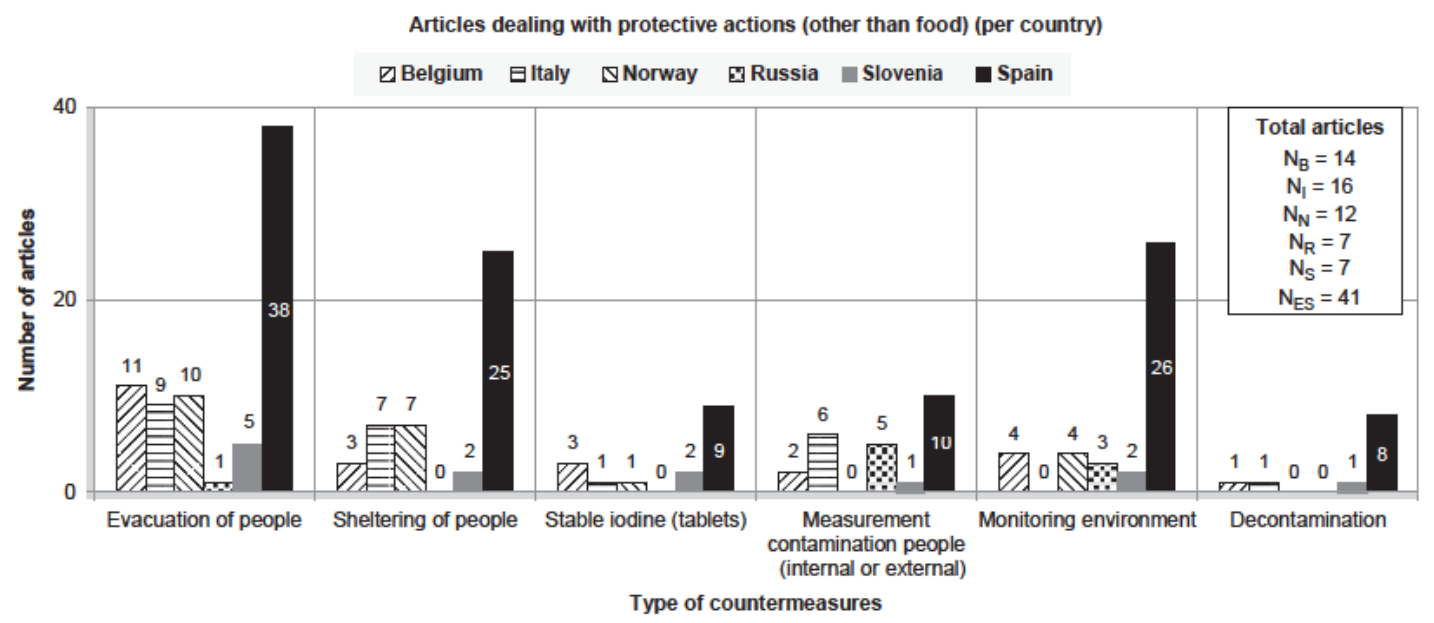

Figure 4. Total number of articles dealing with protective actions (excluding food) covered by the media per country.

(n)

more attention at Weeks $3-4-5$, since focus moved at that moment to the leakage of large amounts of contaminated water directly to the sea surrounding Fukushima-Daiichi NPP.

\section{CONCLUSIONS}

The results of the analysis on the nuclear emergency management phase covered by the media show a lower focus on preparedness and a higher focus on crisis response and recovery/evaluation. It seems that media from countries that produce nuclear energy covered the crisis response much more intensively than media from countries without nuclear energy production. On the contrary, media from nonnuclear countries dedicated more space and time to the recovery and evaluation part of nuclear emergency management.

Public communication is one of the most followed aspects of a nuclear emergency management. In particular, evacuation has to be communicated intensively not only to evacuees but also to a global public worldwide. Media are interested in evacuation since it can be presented as an event. Long-duration sheltering of the population, measurement of people's contamination, especially of iodine in thyroid of 


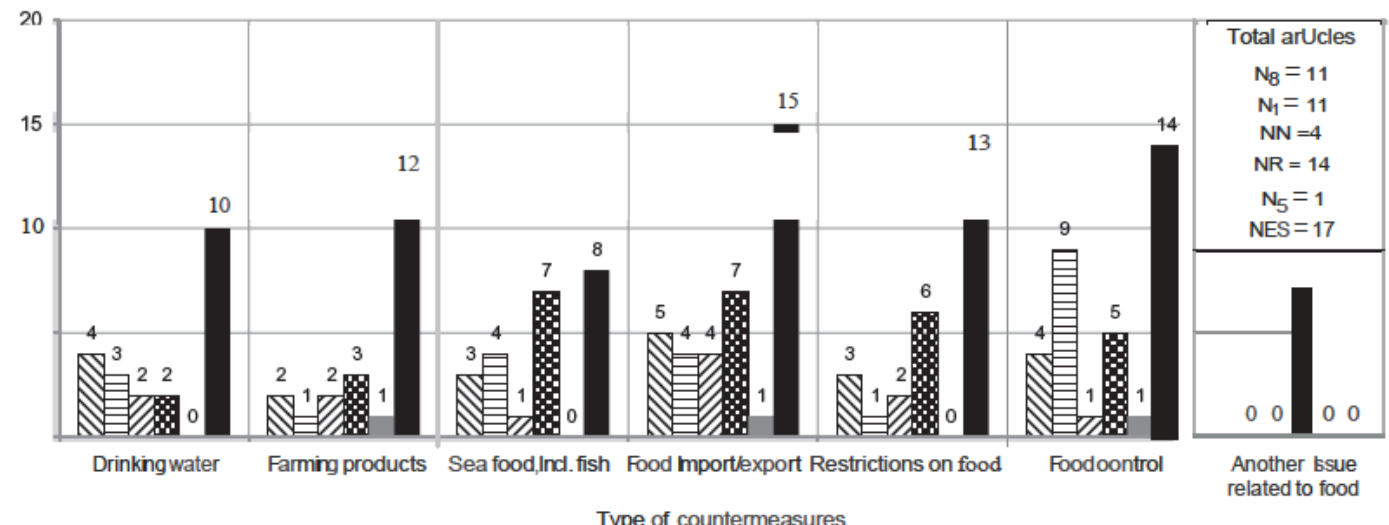

Figure 6. Distribution of the total nwnber of articles dealing with protective actions affecting food covered by the media per country.

Table 1. Number of articles dealing with protective actions affecting food covered by the media per week.

\begin{tabular}{|c|c|c|c|c|c|c|c|c|c|c|}
\hline Topic & 'Mlek 1 & Week 2 & Week 3 & Week 4 & Week 5 & 'Mlek 6 & Week 7 & Week 8 & Week 9 & Total \\
\hline Drinking water & 0 & 14 & 6 & 0 & 1 & 0 & 0 & 0 & 0 & 21 \\
\hline Farming products & 0 & 13 & 4 & 2 & 1 & 0 & 0 & 1 & 0 & 21 \\
\hline Sea food, including fish & 2 & 4 & 5 & 5 & 4 & 1 & 0 & 2 & 0 & 23 \\
\hline Food import/export & 1 & 15 & 7 & 4 & 4 & 2 & 0 & 3 & 0 & 36 \\
\hline Restrictions on food & 0 & 11 & 3 & 4 & 3 & 1 & 0 & 3 & 0 & 25 \\
\hline Food control & 1 & 16 & 4 & 5 & 3 & 2 & 0 & 3 & 0 & 34 \\
\hline Another issue related to food & 1 & 5 & 1 & 0 & 0 & 0 & 2 & 0 & 0 & 9 \\
\hline Articles per week & 2 & 25 & 10 & 7 & 7 & 2 & 2 & 3 & 0 & 58 \\
\hline
\end{tabular}

children, and the use of Iodine tablets as a prophylactic measure are also topics of media Interest.

Even under uncertainty and recognising their limitations, transparent, clear, understandable Information must be provided to the public and the mass media since the beginning of the early phase of any nuclear emergency by the responsible authorities. Falling to do that may seriously harm the credibility of authorities and cause large difficulties In management of the situation In the longer term. Even from the distant European countries, this was a clear lesson learnt from many articles.

Plans and procedures to deliver the public Information response should be developed In advance of any emergency $<{ }^{1.2}>$. As part of emergency preparedness, agencies In charge of the Implementation of protective measures should assess In advance the most common questions demanded by media to the nuclear emergency management during the event and, accordingly, develop clear Information on the main features of the different countermeasures that can be applled.
During the early phase of an event, It ls already necessary to communicate about water consumption Issues, followed by fishing and farming products Issues. Food control measures, as well as for other goods, can also be necessary In case of a nuclear accident happening In a foreign country.

Clear, concise messages should be given. Mass media could play a key role In reassuring the public If proper messages are conveyed by different channels and the countermeasures clearly explained.

\section{ACKNOWLEDGEMENT}

The authors thank the Russian Nuclear Safety Institute for coding of the collected media articles In Russian language.

\section{FUNDING}

This work was supported by the European Atomic Energy Community Seventh Framework Programme (FP7/2007 2011) (FP7/2012 2013) (Grant agreement 
number 323287]; and by the related Norwegian Research Council PREPARE project [226135].

\section{REFERENCES}

1. International Atomic Energy Agency. Communication with the public in a nuclear or radiological emergency. EPR-Public Communications 2012. (Vienna: IAEA) (2012).

2. International Atomic Energy Agency. Method for devel oping a communication strategy and plan for a nuclear or radiological emergency. EPR Public Communication Plan 2015. (Vienna: IAEA) (2015).

3. Perko, T., Prezelj, I., Tomkiv, Y., Oughton, D. H., Cantone, M. C. and Gallego, E. Final recommendations for improvement of communication with media for nuclear/radiological emergency management. PREPARE Project Report D 6.17: WP6_15_10 (2015)

4. Perko, T, Tomkiv, Y., Oughton, D. H., Cantone, M. C., Gallego, E., Prezelj, I. and Byrkina, E. Units related to radiation exposure and radioactivity in mass media : the Fukushima case study in Europe and Russia. Rad. Prot. Dosim. 164(1/2), 154159 (2015) http://dx.doi.org/ doi:10.1093/rpd/ncu328.

5. Krippendorff, K. Reliability in content analysis. Hum. Commun. Res. 30(3), 411433 (2004).

6. Neuendorff, K. The Content Analysis Guidebook (Thousand Oaks, CA: Sage Publication) (2002).

7. Krippendorf, K. Content Analysis: An Introduction (Beverly Hills, CA: Sage Publication) (1980).

8. Krippendorff, K. Agreement and information in the reli ability of coding. Commun. Methods Meas. 5, 93112 (2011). 